\title{
PROCESSOS DE ENCOURAÇAMENTO DE LEITOS FLUVIAIS: SISTEMATIZAÇÃO DE BASES TEÓRICAS
}

\author{
Guilherme Eduardo Macedo $\operatorname{Cota}^{(\mathrm{a})}$, Caique Alves da Silva ${ }^{(\mathrm{b})}$, Luiz Fernando de Paula Barros ${ }^{(\mathrm{c})}$, \\ Antônio Pereira Magalhães Júnior ${ }^{(d)}$
}

(a) Graduando em Geografia na UFMG, E-mail: guilhermebhmg@ hotmail.com

${ }^{(b)}$ Graduando em Geografia na UFMG, E-mail: caiquealvesgeo@gmail.com

(c)Professor do Departamento de Geografia da UFMG, E-mail: luizfpbarros@yahoo.com.br

(d)Professor do Departamento de Geografia da UFMG, E-mail: magalhaesufmg@yahoo.com.br

\section{Eixo: SISTEMAS GEOMORFOLÓGICOS: ESTRUTURA, DINÂMICAS E PROCESSOS}

\begin{abstract}
Resumo
Os processos de encouraçamento fluvial se referem à presença de sedimentos imóveis (ou imediatamente imóveis) nas calhas de cursos d'água, impedindo a remoção de grãos potencialmente transportáveis. Assim, é formado um pavimento detrítico na superfície do leito, que oferece resistência aos processos abrasivos. Apesar de serem amplamente discutidos na literatura internacional, há poucas contribuições em âmbito nacional para os estudos sobre encouraçamento. Não obstante estejam presentes em diversos trabalhos, as pesquisas sobre encouraçamento fluvial utilizam critérios hidrológicos em detrimento de abordagens de cunho geomorfológico, evidenciando uma lacuna nos estudos da temática com este viés. De modo a contribuir com os estudos sobre encouraçamento em âmbito nacional, o presente trabalho se propõe a realizar uma sistematização das bases teórico-conceituais sobre processos de encouraçamento de calhas fluviais na literatura nacional e internacional, abordando os seus principais problemas e desafios conceituais.
\end{abstract}

Palavras chave: Encouraçamento fluvial; geomorfologia fluvial; níveis deposicionais aluviais.

\section{Introdução}

Os processos de encouraçamento de leitos fluviais (bed armouring) se referem à presença de sedimentos imóveis (ou imediatamente imóveis) nas calhas fluviais, impedindo a remoção de grãos potencialmente transportáveis (BRIDGE, 2003). Desse modo, é formado um pavimento detrítico na superfície do leito do rio, que oferece grande resistência aos processos abrasivos (FRINGS, 2008). Assim, somente os materiais de granulometria mais fina (argiloso a arenoso) que recobrem estes pavimentos são transportados (CHARLTON, 2008).

O equilíbrio hidrossedimentológico, portanto, é alterado, gerando uma perturbação no sistema fluvial, tendo em vista que novas relações entre produção, transporte e deposição de sedimentos passam a vigorar (BARROS, 2010). As novas condições de transporte de material, portanto, influenciam e modificam a geometria do canal, que num processo de retroalimentação também influenciam a vazão e o transporte de 
sedimentos. Consequentemente, o impacto da imobilização dos sedimentos pode ocasionar um colapso na estabilidade do sistema fluvial. O canal tende a migrar lateralmente e a erodir suas margens, aumentando a largura do curso d'água (XU, 1996; VERICAT et al., 2006). Apesar de serem mais comuns na literatura internacional (CHIN, 1999; BRIDGE, 2003; CHARLTON, 2008), são raros os trabalhos que se debruçam sobre propostas metodológicas para o estudo do encouraçamento de calhas fluviais, bem como sobre a gênese dos pavimentos detríticos. Tanto que, consequentemente, não há uma única definição para determinar o que seriam leitos fluviais encouraçados, bem como sobre sua abrangência temporal e espacial.

Em âmbito nacional, os estudos sobre encouraçamento são escassos, com destaque para os trabalhos de Magalhães Júnior et al. (2008) e Stevaux et al. (2009), que identificam trechos de vale encouraçados e os correlacionam com a litologia, no caso do primeiro, e com a interferência de atividades antrópicas, no caso do segundo.

Diante da carência de estudos relativos à temática do encouraçamento no âmbito da geomorfologia fluvial, o presente trabalho se propõe a realizar uma sistematização das bases teórico-conceituais sobre processos de encouraçamento de calhas fluviais na literatura nacional e internacional, abordando os seus principais problemas e desafios conceituais. São realizadas reflexões sobre os fatores condicionantes da formação de pavimentos detríticos, bem como sobre sua gênese e sua influência para a dinâmica subsequente dos cursos d'água.

\section{Processos de encouraçamento de leitos fluviais (bed armouring): bases conceituais e teóricas}

A literatura, de maneira geral, descreve os processos de encouraçamento fluvial como a formação de um pavimento detrítico no leito de um curso d'água que, por alterações na capacidade e/ou competência do fluxo, mantem seus grãos imóveis ou temporariamente imóveis (GOUDIE, 2004; ALMEDEIJ \& DIPLAS, 2005; BRIDGE, 2003; VERICAT et al., 2006; FRINGS, 2008).

Em seus estudos sobre encouraçamento e/ou a gênese de couraças ferruginosas pleistocênicas de origem fluvial no Quadrilátero Ferrífero, Magalhães Júnior et al. (2008), Barros (2010) e Barros et al. (2016) destacam que para esta unidade geológica-geomorfológica, a alta presença de ferro dissolvido das formações ferríferas bandadas (Banded Iron Formations - BIF's) e sua posterior precipitação em ambiente de fundo de vale - pela oscilação do nível freático - favorecem a cimentação ferruginosa do material mais grosso. Assim, o encouraçamento não é compreendido apenas pelos sedimentos "soltos", porém imóveis sobre o leito, mas também pela cimentação ferruginosa destes materiais que, por sua vez, ficam mais resistentes à ação do fluxo. 
Charlton (2008) e Curran \& Tan (2010) destacam que o fenômeno de encouraçamento está associado a uma redução do fluxo d'água por períodos estendidos, tornando-o incapaz de transportar os materiais de granulometria mais grosseira (seixo e cascalho). Na medida em que esse material é depositado na calha, há um aumento da rugosidade do leito e uma diminuição da força erosiva do fluido, o que decorre do atrito do fluxo com as partículas de granulometria variada e que, associadas às irregularidades do canal, requerem uma maior energia para movimentação (CHARLTON, 2008; CURRAN \& TAN, 2010; BARROS, 2010; HEAYS, 2011). Estes depósitos imóveis em ambiente de calha geram clusters, também identificados como agrupamentos de sedimentos de granulometria variada que permanecem praticamente imóveis no leito fluvial (BILLI, 1988; CURRAN \& TAN, 2010).

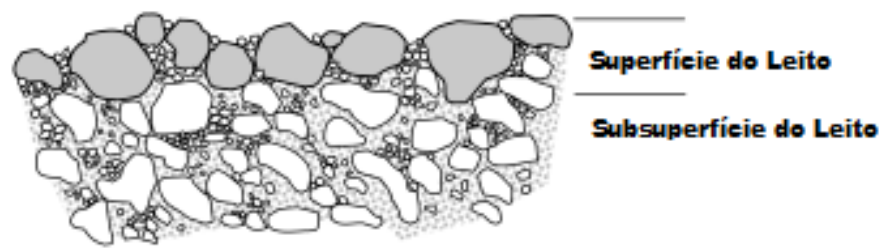

Figura 1: Representação de partículas imóveis sobre o leito fluvial recobrindo outras partículas.

Fonte: adaptado de Almedej \& Diplas (2005).

O tamanho e o arranjo dos sedimentos depositados podem, ainda, afetar a movimentação de outras partículas menores na superfície do leito (CHARLTON, 2008). Isso se dá em decorrência da disposição espacial dos materiais na calha fluvial, que pode aumentar o ângulo de atrito das partículas quando os materiais de granulometria mais fina se sobrepõem aos de granulometria maiores, requisitando maior energia para sua movimentação. Charlton (op. cit.) afirma que, no caso de um arranjo espacial onde os materiais mais grossos sobrepõem os mais finos, mesmo que parcialmente, ou ofereçam resistência à ação do fluxo em direção a estes, as partículas menores permanecem imóveis.

É possível inferir, portanto, que mesmo o processo de encouraçamento sendo caracterizado pela imobilização das partículas que não respondem mais a capacidade e competência do fluxo, materiais potencialmente transportáveis passam, também, a ficar imóveis pelo contato com sedimentos mais grossos já depositados. Assim, os clusters gerados podem não ser compostos apenas por seixos e cascalhos, mas também por sedimentos mais finos que, em contato com o material mais grosso, também permanecem imóveis no leito fluvial. Nesse sentido, Almedeij \& Diplas (2005) afirmam que os grãos finos podem, ainda, penetrar nos espaços entre as partículas maiores em direção à base do pavimento, favorecendo a formação de um substrato rico em sedimentos finos.

O pavimento detrítico que recobre o leito fluvial, portanto, limita e/ou impede que processos abrasivos ocorram, cessando, mesmo que parcialmente, as taxas de incisão vertical do canal. Xu (1996), Vericat et 
al. (2006) e Barros (2010) destacam que um leito fluvial encouraçado tende a dispensar sua energia se expandindo ou migrando lateralmente.

Para além das influências na morfodinâmica do canal fluvial, os processos de encouraçamento também possuem importância em termos biológicos. Nesse sentido, Wilcock \& DeTemple (2005) e Heays (2011) afirmam que os sedimentos imóveis em ambientes de calha servem de habitat para insetos aquáticos e para a desova de algumas espécies de peixes.

\section{Condicionantes (paleo)ambientais para a formação de pavimentos detríticos}

$\mathrm{Na}$ literatura investigada sobre os processos de encouraçamento, diversos trabalhos associam sua ocorrência a cursos d'água de leito de cascalho (gravel-bed river) (BILLI, 1988; GOUDIE, 2004; WILCOCK \& DETEMPLE, 2005; VERICAT et al., 2006; CHARLTON, 2008; CURRAN \& TAN, 2010). Neste sentido, Gomez (1983) e Almedej \& Diplas (2005) destacam que rios em leito de cascalho possuem material de calha composto por granulometria estratificada, não sendo bem selecionada. Consoante, o tamanho do material presente na calha varia desde $2 \mathrm{~mm}$ até um limite superior não precisamente identificado, apesar de Goudie (2004) afirmar a necessidade de se distinguir de leitos compostos por materiais muito grandes, particularmente blocos e matacões ( $>256 \mathrm{~mm})$.

Como os materiais de granulometria mais fina são transportados pela ação do fluxo, os materiais mais grossos permanecem imóveis recobrindo outros materiais de granulometria mais fina subjacente (GOUDIE, 2004). O referido autor ainda afirma que é possível ocorrer processos de encouraçamento em rios de leito de areia que contêm pouco cascalho, sendo que este fica concentrado na superfície como um depósito estável (stable lag deposit).

Dentre os trabalhos investigados, no entanto, poucos fazem associação à gênese dos processos de encouraçamento, com exceção dos trabalhos de Goudie (2004) e Barros (2010). Conquanto, parte significativa dos trabalhos se preocupa com aspectos hidrológicos para definir as condições de fluxo necessárias para garantir o equilíbrio do pavimento detrítico e para romper a camada de sedimentos imóveis sobre o leito (LARONNE et al., 1994; EMMETT \& WOLMAN, 2001; WILCOCK \& DETEMPLE, 2005; VERICAT et al., 2006), em detrimento de uma análise sistêmica, associada à morfodinâmica e/ou à morfogênese do sistema fluvial. Deste modo, processos geomorfológicos que poderiam auxiliar no entendimento desta alteração nas condições hidrossedimentológicas permanecem no ostracismo em decorrência da valoração de aspectos puramente hidrológicos.

Possíveis alterações nos níveis de base do canal fluvial alteram a dinâmica erosiva e deposicional da bacia, favorecendo a dissecação do vale ou a predominância de processos agradacionais. Benn \& Erskine (1994) e Vericat et al. (2006) demonstram que esta alteração dos níveis de base é característica de cursos d'água 
XVII Simpósio Brasileiro

de Geografia Física Aplicada

I Congresso Nacional

de Geografia Física
OS DESAFIOS DA GEOGRAFIA FÍSICA NA FRONTEIRA DO CONHECIMENTO

Instituto de Geociências - Unicamp

Campinas - SP

28 de Junho à 02 de Julho de 2017

que possuem barragens, tendo em vista que o barramento impede o transporte de sedimentos grossos e uma porcentagem dos materiais finos de montante para jusante. Os referidos autores ainda afirmam que o controle da vazão defluente nas barragens diminui a capacidade e competência do curso d'água, favorecendo processos de agradação e de formação de um pavimento detrítico no leito fluvial.

Barros (2010) destaca, também, que alterações nas condições de fluxo responsáveis pelo transporte e deposição de materiais podem ser geradas por rebaixamentos do nível de base à jusante ou pelo seu soerguimento local, dando um input energético ao sistema. Em uma lógica inversa, onde há um soerguimento do nível de base à jusante ou um rebaixamento local, ocorrerá perda de energia no sistema fluvial, favorecendo, processos de agradação. Um soerguimento a montante também pode gerar um incremento na carga de sedimentos para a bacia. Outros fatores como perda ou ganho de áreas por capturas fluviais, variações climáticas e pertubações tectônicas podem, por sua vez, alterar a capacidade e competência dos cursos d'água.

Laronne et al. (1994) e Almeidj \& Diplas (2005) inferem, ainda, que em cursos d'água efêmeros o processo de encouraçamento ocorre de maneira diferente. Dada sua predominância em ambientes áridos e semiáridos, os cursos d'água efêmeros adquirem fluxo somente durante as cheias, o que, consequentemente, gera o transporte de todo o material no fundo do leito, mesmo os sedimentos presentes nos estratos inferiores (LARONNE et al., 1994; ALMEDJ \& DIPLAS, 2005). Assim, o transporte seletivo de material típico de leitos perenes (retirada dos finos e manutenção dos mais grossos) fica comprometido, impedindo muitas vezes a formação de um pavimento. Consoante, Laronne et al. (1994) afirmam que, dado o fato de rios efêmeros transportarem todo o material de leito de maneira não seletiva, os processos de encouraçamento neste caso são de origem sin-deposicional, em contraste com leitos perenes.

Goudie (2004) ainda afirma que variações no fornecimento de material sedimentar para os cursos d'água podem promover alterações nas taxas de transporte de material de leito. Assim, cursos d'água com elevado aporte sedimentar irão responder com taxas de transporte de leito análogas a cursos d'água com pouco fornecimento de material detrítico. Deste modo, é possível inferir que, durante um momento de maior agradação do vale fluvial, pode ocorrer o entulhamento da seção do canal, com materiais de granulometria superior à capacidade e competência do curso d'água, favorecendo a ocorrência de processos de encouraçamento. Esses processos são predominantes em regiões montanhosas, onde há o fornecimento de material grosso e mal classificado para o canal fluvial (Goudie, 2004).

Leopold et al. (1964) e Barros et al. (2016) apontam que em vales com encostas íngremes e com ausência de vegetação, podem prevalecer processos mecânicos, sobretudo no transporte de cascalho e areia para o fundo de vale. 
Para ambientes úmidos, no entanto, mesmo em condições de encostas íngremes, a maior presença de vegetação nas encostas dificulta a retirada mecânica do material das encostas e sua deposição nos fundos de vale. Assim, o entulhamento dos sistemas fluviais em ambiente úmido pode estar relacionado a um paleoambiente mais seco. Barros et al. (2016), no estudo sobre os paleoambientes do Quadrilátero Ferrífero, afirma que durante os períodos mais secos ocorreu a agradação dos vales fluviais, dando origem a depósitos fluviais expressivos de cascalho e areia.

A erosão de antigos níveis deposicionais aluviais, mais precisamente das fácies grosseiras (cascalhos e seixos), também pode fornecer material detrítico para os fundos de vale. Esse processo é mais intenso em regiões tropicais pela maior atuação de movimentos de massa e outros processos de vertente (OLIVEIRA, 2012).

Contudo, há duas situações que precisam ser individualizadas: uma é o fornecimento de material mais grosso de um nível aluvial elevado em relação à calha atual; a outra é a erosão dos finos de um nível aluvial no mesmo nível da calha atual, deixando os materiais grossos como "resíduo".

No entanto, é preciso ter cautela ao associar o material detrítico de fundo de vale com antigos níveis deposicionais aluviais, pois, conforme aponta Charlton (2008), estes níveis são preservados apenas como fragmentos e não linearmente ao longo do vale, sendo que, mesmo após serem erodidos, podem não representar toda a disposição espacial dos pavimentos detríticos presentes na calha fluvial.

\section{Escala temporal, escala espacial e complexidade na formação de processos de encouraçamento}

Conforme explicitado no tópico anterior, a grande maioria dos trabalhos que investigam os processos de encouraçamento se restringe somente à força necessária do fluxo para manter o pavimento detrítico estável, para romper e/ou movimentar essa camada de material que se encontra imóvel. Assim, outas associações com a temporalidade e a espacialidade do fenômeno são escassas.

No que tange à sua escala temporal, diversos trabalhos associam a ocorrência dos pavimentos detríticos a uma diminuição da vazão do canal durante períodos secos, quando não há competência para carregar materiais de granulometria grosseira (GOMEZ, 1983; CHARLTON, 2008; CURRAN \& TAN, 2010). Sob esta lógica, seria possível associar os processos de encouraçamento à variação sazonal no regime pluviométrico. No entanto, Billi (1988) em seu estudo sobre leitos encouraçados na porção central da Itália mostra que não é possível estabelecer uma temporalidade precisa para a ocorrência de processos de encouraçamento, pois mesmo durante eventos de inundação, os clusters formados podem não se alterar. Ele ainda afirma que a taxa de destruição e (re)construção dos clusters não permanece igual a cada evento de inundação. 
Deste modo, a identificação de trechos encouraçados em campo se torna complexa, pois a simples associação de sedimentos potencialmente imóveis no leito com trechos encouraçados exclui a possibilidade de estes sedimentos estarem sofrendo algum tipo de transporte, tendo em vista que o material de calha responde às diversas variações de fluxo, podendo estar imóvel em um determinado momento, mas estar sendo transportado quando às condições de fluxo retornem à taxa necessária para o seu transporte.

Assim, torna-se necessária uma análise acerca da estabilidade destes clusters ao longo do tempo, visando estabelecer se estes materiais realmente estão imóveis. Não obstante, mesmo não havendo uma escala temporal específica para determinar se um leito está encouraçado ou não, a afirmação de diversos autores que os sedimentos permanecem imóveis durante baixos fluxos leva a entender que os processos de encouraçamento estão associados a estas condições, apesar de, conforme destaca Billi (1988), trechos encouraçados poderem permanecer intactos mesmo em períodos de maior fluxo.

Numa tentativa de associar leitos encouraçados às mudanças na morfologia do canal, é possível pensar em uma escala temporal mais ampla para a estabilidade dos pavimentos detríticos. Neste caso, além das condições de fluxo, transporte, deposição e descarga sedimentar, também devem ser consideradas outras variáveis, como o material constituinte das margens que, por sua vez, determinarão sua capacidade de coesão e a maneira como ocorrerá os processos de acresção lateral (SCHUMM \& KAHN, 1972). No entanto, não há na literatura investigada nenhum postulado metodológico para determinação de trechos encouraçados a partir de mudanças na morfologia do canal.

Diversos métodos para quantificar o transporte sedimentar dos cursos d'água são amplamente discutidos na literatura (Cf. CHRISTOFOLETTI, 1981; $C f$. SCAPIN et al., 2007). Nesse sentido, Scapin et al. (op. cit.) destaca as fórmulas de Meyer Peter e Müler (descarga de sedimentos por arrasto de fundo), Einstein (estimativa para descarga de material de fundo em diferentes vazões), Karim (descarga total de sedimentos por unidade de largura) e Cheng (transporte de sedimentos em condições de cisalhamento moderadas e altas).

Contudo, apesar de sua importância, a escala espacial para a determinação do transporte sedimentar se restringe somente a uma seção do canal ou a um trecho fluvial, não abrangendo uma bacia hidrográfica ou um curso d'água por completo, sendo que para isso é necessária uma sucessão de cálculos para cada seção fluvial, o que torna inviável sua aplicabilidade em estudos de menor escala.

Assim, sua validade para estudos geomorfológicos é questionada, pois trabalhos sobre geomorfologia fluvial normalmente utilizam uma escala tanto espacial quanto temporal mais abrangente. Apesar do passado geomorfológico ser estudado com base em evidências atuais, a história de um sistema fluvial não 
pode se basear em critérios que retratem somente as condições hidrossedimentológicas atuais e não faça relações com sua dinâmica pretérita e/ou em paleoambientes.

Aberle \& Nikora (2006), Gao (2011) e Heays (2011) também afirmam que nenhuma equação pode ser aplicada universalmente para qualquer curso d'água, tanto que nos estudos sobre encouraçamento as equações são estabelecidas para cada área de trabalho específica. Assim, não há um modelo hidrológico que estabeleça uma equação para determinar a força de fluxo necessária para o transporte de um material de determinada granulometria que possa ser aplicado para qualquer curso d'água. Soma-se a isso o fato de que os modelos de previsão de resistência à ação do fluxo estão sujeitos a erros e discrepâncias nos valores finais, muito em decorrência da escolha dos parâmetros utilizados e nos métodos para o cálculo destes parâmetros como, por exemplo, a definição da rugosidade do leito (POWELL, 2014).

No que tange à disposição espacial dos clusters, Heays (2011) afirma que estes agrupamentos de sedimentos são gerados pelo transporte seletivo que caracteriza os pavimentos detríticos e que são mais estáveis que os materiais circundantes, gerando diversas microformas pela deposição do material em leito. Consoante, é possível inferir que, ao menos espacialmente, trechos encouraçados podem estar associados à ocorrência destas microformas. Em seu estudo sobre a formação destes agrupamentos de sedimentos, Strom et al. (2005) e Heays (2011) identificam cinco tipos de clusters principais (Figura 2).

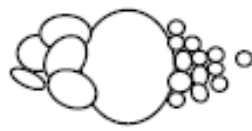

Cluster Típico

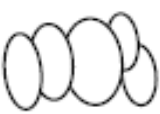

Cluster de Linha

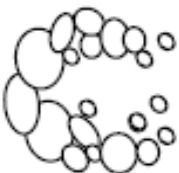

Comet Cluster

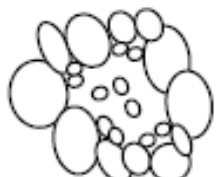

Cluster de

Anel

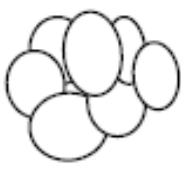

Heap Cluster

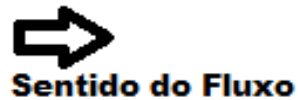

Figura 2: Diferentes tipos de clusters. Fonte: adaptado de Strom et. al. (2005).

A presença destes clusters, portanto, fomenta os processos de oscilação do fluxo na medida em que promove sua divergência no contato com os clusters e sua posterior convergência à jusante deste (HEYS, 2011). Este processo vai de encontro à discussão de Montgomery \& Buffington (1998), que afirmam que esta oscilação no fluxo é responsável pela formação de leitos em poço-corredeira (pool-riffle) e que estes comumente encontram-se encouraçados.

A configuração espacial destes clusters, portanto, está associada às células de fluxos internos (divergência nos rifles e convergência nos pools). Para explicar este fenômeno, Keller (1971) apud Fernandez et al. (2002), estabeleceu a hipótese da reversão da velocidade do fluxo (hypothesys of velocity reversal). 
Partindo do pressuposto que, sob vazões reduzidas, a velocidade do fluxo é maior nas corredeiras do que nos poços, em condições de maior vazão, essa lógica se inverte, tornando a velocidade do fluxo maior nos poços do que nas corredeiras.

Consoante, sob vazões reduzidas, predominam o transporte seletivo de material típico dos processos de encouraçamento nas corredeiras e a deposição dos materiais de granulometria mais fina nos poços. Conquanto, durante os períodos de maior fluxo, quando há a reversão da velocidade, ocorre uma maior remoção do material no poço do que em relação às corredeiras, gerando um aprofundamento do canal nestes locais (FERNANDEZ et al., 2002). Apesar de esta hipótese não ser totalmente aceita, Fernandez et al. (2002) afirma que o fenômeno da reversão da velocidade do fluxo já foi incorporado por vários cientistas e pode ser entendida como um postulado para posteriores investigações.

Sob esta ótica, portanto, trechos de leitos encouraçados não precisam necessariamente estar associados somente aos materiais imóveis in situ conforme destacam BRIDGE (2003), ALMEDEJ \& DIPLAS (2005), VERICAT et al. (2006), GOUDIE (2006) e FRINGS (2008), mas sim a uma morfologia de leito que caracterize segmentos encouraçados. Montgomery \& Buffington (1998), Magalhães Júnior et al. (2008) e Messias \& Magalhães Júnior (2014) corroboram com esta afirmação ao associarem a ocorrência de processos de encouraçamento a leitos cuja morfologia é composta por poço-corredeira.

\section{Considerações finais}

A sistematização das bases teórico-conceituais referentes ao processo de encouraçamento permitiu realizar apontamentos sobre os principais problemas e desafios conceituais presentes na literatura, sobretudo para as pesquisas de cunho geomorfológico. É evidente a presença predominante de estudos relacionados ao encouraçamento sob a ótica hidrológica, em detrimento de estudos com viés geomorfológico, gerando lacunas que, pelo menos em parte, prejudicam a compreensão dos condicionantes da presença de pavimentos detriticos para a morfologia e para a morfodinâmica do canal fluvial.

Consoante, diversos fatores relacionados à alteração dos níveis de base, paleoambientes e à erosão de antigos níveis deposicionais aluviais podem influenciar a formação de pavimentos detríticos, alterando a mofodinâmica do canal e, consequentemente, sua morfologia. Nesse sentido, é possível inferir, baseado na disposição espacial dos clusters, que os processos de encouraçamento podem estar associados à morfologia de leito em poço-corredeira. Contudo, poucos estudos buscam essa associação, sendo que nenhum propõe uma abordagem metodológica própria para o estudo dos processos de encouraçamento. Não obstante, as discussões acerca da disposição espacial e temporal dos pavimentos detríticos utilizam critérios puramente hidrológicos que, conforme a metodologia aplicada, são passíveis de erros e críticas. 


\section{Bibliografia}

ABERLE, J.; NIKORA V. Statistical properties of armoured gravel bed surfaces. Water Resources Research, v. 42, p. 1-11, 2006.

ALMEDEIJ, J.; DIPLAS, P. Bed load sediment transport in ephemeral and perennial gravel bed streams. Eos, v. 86, n. 44, p. 429-434, 2005.

Barros, L. F. P.; COE, H. H. G.; SeIXAS, A. P.; MAGAlhães JÚNIOR, A. P.; MACARIO, K. C. D. Paleobiogeoclimatic scenarios of the Late Quaternary inferred from fluvial deposits of the Quadrilátero Ferrífero (Southeastern Brazil). Journal of South American Earth Sciences, v. 67, p. 71-88, 2016.

BARROS, P. H. C. A. Processos de encouraçamento de calhas fluviais: Panorama teóricoconceitual e o exemplo do Rio Conceição (Quadrilátero Ferrífero-MG). 2010. Monografia (Graduação em Geografia) Universidade Federal de Minas Gerais, Belo Horizonte, 2010.

BENN, P. C.; ERSKINE, W. D. Complex channel response to flow regulation: Cudgegong river below Windamere Dam, Australia. Applied Geography, v. 14, p. 153-168, 1994.

BILLI, P. A note on cluster bedform behavior in a gravel-bed river. Catena, v. 15, p. 473-481, 1988.

BRIDGE, J. S. Rivers and Floodplains. Blackwell Science, Oxford, 2003. 492 p.

CHARLTON, R. Fundamentals of fluvial geomorphology. London; New York: Routledge, 2008. 234 p.

CHIN, A. The morphologic structure of step-pools in mountain streams. Geomorphology, v. 27, p. 191-204, 1999.

CHRISTOFOLETTI, A. Geomorfologia fluvial. São Paulo: Edgar Blucher, 1981. 313 p.

CURRAN, J. C.; TAN, L. An investigation of bed armouring process and the formation of microclusters. In: Joint

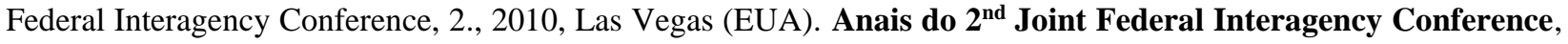
Las Vegas: [s.n.], 2010, Não paginado.

EMMET, W. W.; WOLMAN, M. G. Effective discharge and gravel-bed rivers. Earth Surface Processes and Landforms, v. 26, p. 1369-1380, 2001.

FERNANDEZ, O. V.; Q. SANDER, C.; REBELATTO, G. E. Sequência de Soleiras e Depressões no Córrego Guavirá, Marechal Cândido Rondon, Região Oeste do Paraná. Revista Brasileira de Geomorfologia, v. 3, n. 1, p. 49-57, 2002.

FRINGS, R. M. Downstream fining in large sand-bed rivers. Earth-Science Reviews, v. 87, p. 39-60, 2008.

GAO, P. An equation for bed-load transport capacities in gravel-bed rivers. Journal of Hidrology, v. 402, p. 297 305, 2011.

GOMEZ, B. Temporal variations in bedload transport rates: The effect of progressive bed armouring. Earth Surface Processes and Landforms, v. 8, p. 41-54, 1983.

GOUDIE, A. S. Encyclopedia of Geomorphology. Londres: Routledge, 2004. 1156 p.

HEAYS, K. G. Cluster formation and Stream-bed Armouring: A photogrammetric study. 2011. Tese (Doutorado) - The University of Auckland, Auckland (Nova Zelândia), 2011.

KELLER, E. A. Areal sorting of bed load material: the hypothesis of velocity reversal. Bulletin of the Geological Society of America, v. 82, p. 753-756, 1971.

LARONNE, J. B.; REID, I.; YITSHAK, Y.; FROSTICK L. E. The non-layeringof gravel streambeds under ephemeral flood regimes. Journal of Hydrology, v. 159, p. 353-363, 1994. 


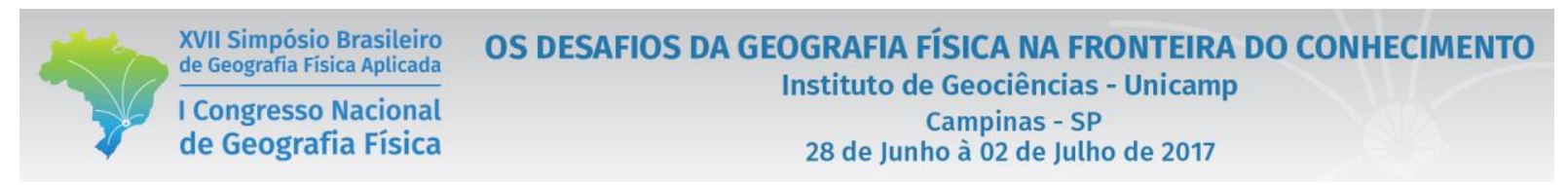

LEOPOLD, L. B.; WOLMAN, M. G.; MILlER, J. P. Fluvial Processes in Geomorphology. San Francisco: Freeman and Company, 1964. 522 p.

MAgAlhães JÚNIOR, A. P.; SANTOS, G. B.; CHEREM, L. F. S. Processos de Encouraçamento da Calha do Alto Rio das Velhas e seus Reflexos na Dinâmica Fluvial Moderna, Quadrilátero Ferrífero, MG. In: II Encontro Latino Americano de Geomorfologia e VII Simpósio Nacional de Geomorfologia, 2008, Belo Horizonte. Anais do VII SINAGEO. Belo Horizonte: Tec Art, 2008. v. 1. p. 120-130.

MESSIAS, R. M.; MAGALHÃES JÚNIOR, A. P. Níveis deposicionais aluviais no vale do Córrego do Rio Grande, Depressão de Gouveia - MG. Revista Geonorte, v. 10, p. 379-384, 2014.

MONTGOMERY, D. R.; BUFFINGTON, J. M. Channel processes, classification, and response. In: NAIMAN, R. J.; BILBY, R. E. River Ecology and Management: Lessons from the Pacific Coastal Ecoregion. New York: Springer, 1998. p. 13-42.

OLIVEIRA, L. A. F. de. A dinâmica fluvial quaternária e a configuração do modelado do relevo no contato entre a Depressão do Rio Pomba e o Planalto de Campos das Vertentes - Zona da Mata de Minas Gerais. 2012. Dissertação (Mestrado em Análise Ambiental) - Instituto de Geociências, Universidade Federal de Minas Gerais, Belo Horizonte, 2012.

POWELL, D. M. Flow resistance in gravel-bed rivers: Progress in research. Earth-Science Reviews, v. 136, p. 301$338,2014$.

SCAPIN, J.; PAIVA, J. B. D. de; BELING, F. A. Avaliação de Métodos de Cálculo do Transporte de Sedimentos em um pequeno Rio Urbano. Revista Brasileira de Recursos Hídricos, v. 12, n. 4, p. 05-21, 2007.

SCHUMM, S. A.; KAHN, H. Experimental study of channel patterns. Bulletin of the Geological Society of America, v. 83, p. 1755-1770, 1972.

STEVAUX, J. C.; PAES, R. J.; FRANCO, A. A.; ETCHEBEHERE, M. L.; FUJITA, R. H. Morphodynamics in the confluence of large regulated rivers: the case of Paraná and Paranapanema rivers. Latin American Journal of Sedimentology and Basin Analysis. v. 16, n. 2, p. 101-109, 2009.

STROM, K. B.; PAPANICOLAU, A. N.; BILlinG, B.; ELY, L. L.; HENDRICKS, R. R. Characterization of particle cluster bedforms in a mountain stream. In: World Water and Environmental Resources Congress, 2005, Anchorage, Alaska, United States. Anais do World Water and Environmental Resources Congress. [s.1.]: [s.n], 2005, p. 1-12.

VERICAT, D.; BATALLA, R. J.; GARCIA, C. Breakup and reestablishment of the armour layer in a large gravelbed river below dams: The lower Ebro. Geomorphology, v. 76, p. 122-136, 2006.

WILCOCK, P. R.; DETEMPLE, B. T. Persistence of armor layers in gravel-bed streams. Geophysical Research Letters, v. 32, p. 1-4, 2005.

$\mathrm{XU}, \mathrm{J}$. Underlyng gravel layers in large sand bed river and their influence on downstream-dam channel adjustment. Geomorphology, v. 17, p. 351-359, 1996. 